
Cell Research(1994),4, 89-96

\title{
The inhibitory effect of transthyretin gene on growth of human hepatoma cells
}

\author{
LiU Chaoting, Jin YAO, Daizong LI, Huiqiu \\ JIANG, JI A R E N GU ${ }^{1}$. \\ National Laboratory for Oncogenes and Related Genes, \\ Shanghai Cancer Institute, Shanghai 200032, China.
}

\section{ABSTRACT}

Transthyretin(TTR) gene was highly expressed in normal liver and it has been found to be deleted in part of DNA samples from human hepatic cancer. Its mRNA expression was suppressed in most hepatoma samples. In order to study the biological effect of TTR gene on the growth of hepatoma cells, a recombinant vector containing TTR cDNA was constructed by pCMV, then it was transfected into hepatoma cell lines SMMC-7721 and Q3. It has been demonstrated that the inhibition of growth rate of TTR cDNA transfected hepatoma cells was about 50\% in strength compared with that of the control. This inhibition was further enhanced when the transfected hepatoma cells were treated with all-trans retinoic acid. Hepatoma cells of cell lines PLC/PRF/5, SMMC-7721 and Q3 as well as hepatoma cells SMMC-7721 transfected with pCMV or pCMV-TTR were analyzed for TTR expression by Northern hybridization. The low level of TTR expression was found in both hepatoma cell lines and in SMMC-7721 cells transfected with pCMV alone. However, a remarkable TTR mRNA expression was observed in hepatoma SMMC-7721 cells transfected with pCMV-TTR. It seems possible that TTR gene might be a candidate of cancer suppressor gene for human hepatic cancer.

Key words: $T T R$ cDNA, hepatoma, growth, RNA, retinoic acid 
Inhibition of hepatoma cell growth by TTR cDNA

\section{INTRODUCTION}

It has been demonstrated that human transthyretin(TTR) gene was deleted in part of DNA samples from human hepatic cancer. In addition, the mRNA expression was suppressed in most hepatic cancer samples[1]. This gene alteration was unexpectedly found in one of the cDNA clones screened from a subtracting cDNA library from normal human liver VS human hepatoma, and, to the best of our knowledge, was described for the first time in human malignancies, particularly human primary hepatic cancer[1]. Previously, TTR gene has been recognized to be linked with familial amyloidosis[2-4], thyroxine transport and involved in the complex formation of the retinol binding protein and retinol $(\mathrm{RBP} / \mathrm{R})$. In this report, the growth behavior of human hepatoma cells was analyzed after their transfection with TTR cDNA. The results indicated that the growth rate of hepatoma cells was inhibited either by TTR transfection alone or in combination with the treatment of all trans-retinoic acid. The possible cancer-suppressive action of TTR gene for human hepatic cancer was discussed.

\section{MATERIALS AND METHODS}

\section{Cell lines}

Of the human hepatoma cell lines used, SMMC-7721 was donated from the Second Military Medical University; Q3 from Shen Cuiying (Department of Immunology and Cell Biology, this Institute) and PLC/ PRF /5 from Dr. Wen Yumei (Shanghai Medical University). All these cells were grown in Dulbecco's Modified Eagle's Medium supplemented with 15\% fetal calf serum, $100 \mathrm{U} / \mathrm{ml}$ penicillin and $100 \mu \mathrm{g} / \mathrm{ml}$ streptomycin, and were used for transfection and for growth rate studies.

\section{TTR cDNA constructs}

A clone of full-length TTR cDNA screened from a cDNA library constructed with mRNA from normal human liver (3II) had a total $0.5 \mathrm{~kb}$ nucleotides of coding sequence. The cDNA was inserted into an expression vector $\mathrm{pCMV}$ at BamH1 site, driven by CMV promoter (pCMV vector, as a gift from Dr. Curtis Harris, NCI, NIH). This new plasmid construct designated as pCMV-TTR was used for DNA transfection and its physical map was shown in Fig 1.

Fig 1. Physical map of the expression plasmid $\mathrm{pCMV}$ vectors containing human TTR cDNA in sense orientation. Human TTR cDNA fragment $(0.5 \mathrm{~kb})$ cloned into BamH1 site of vector pCMV (6.55 kb). Symbols: human TTR cDNA $\square$, CMV promoter

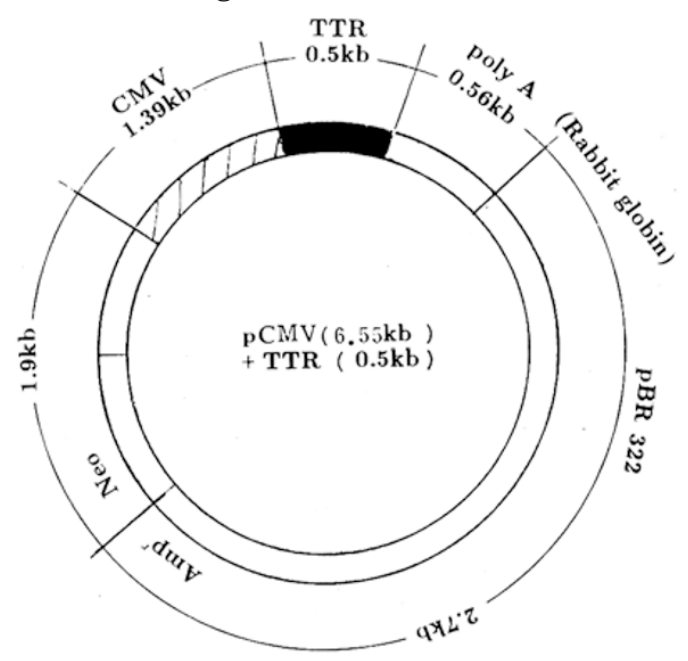




\section{Transfection of pCMV-TTR into human hepatoma cells}

pCMV- TTR or pCMV DNA at a dose of $15 \mu \mathrm{g}$ was used for transfection by lipofecin ${ }^{T M}$ reagent (Bethesda Research Laboratories, Life Technologies, Inc.) as described previously[5]. Briefly, SMMC-7721, PLC /PRF/5, or Q3 cells were incubated at $37{ }^{\circ} \mathrm{C}$ and $5 \% \mathrm{CO}_{2}$ until they reached $70 \%$ confluency.The cells werw washed twice with an appropriate serum-free medium. The serumfree medium $(3 \mathrm{ml})$ was added to the cells, then lipofectin ${ }^{T M}$ reagent-DNA complex was added and mixed. The cells were incubated for $20 \mathrm{~h}$. The medium was replaced by fresh DMEM with $15 \%$ fetal calf serum. The cells were grown for another $48 \mathrm{~h}$. G-418 $(400 \mu \mathrm{g} / \mathrm{ml})$ was used for the selection for neo resistance. Individual colonies were isolated after $14 \mathrm{~d}$ of selection with G418, and propagated individually to confluence. Hepatoma cells transfected by both pCMV-TTR and pCMV were used for comparision of their growth behavior.An amount of $1.4 \times 10^{5}$ cells per T25 tissue culture flask was seeded on $\mathrm{d} 0$, and cells were counted at $\mathrm{d} 2, \mathrm{~d} 4$ and $\mathrm{d} 6$, and were used for RNA extraction.

\section{RNA analysis}

Total RNA was isolated from hepatoma cells (PLC/PRF/5, Q3, SMMC-7721) and SMMC7721 transfected with pCMV and pCMV-TTR. The colonies of the transfected hepatoma cells were isolated $14 \mathrm{~d}$ after G418 selection and propagated for RNA isolation using the acid guanidiniumphenol-chloroform (AGPC) ${ }^{2}$ method[6]. Northern transfer and hybridization with TTR probe (0.5 $\mathrm{kb}$ ) were carried out according to the techniques described by T. Maniatis et al.[7]. The probe was labeled by ${ }^{32} \mathrm{P}$-(a)dCTP using random primer techniques according to the manufacturer's protocol (BRL), with a specific radioactivity at $>10^{8} \mathrm{cpm} / \mu \mathrm{g}$ DNA. The filters hybridized with TTR probe were washed twice in $1 \times \mathrm{SSC}, 0.1 \% \mathrm{SDS}$ and twice $0.1 \times \mathrm{SSC}, 0.1 \% \mathrm{SDS}$ at room temperature. Autoradiography was carried out using Kodak XAR film.

\section{Retinoic acid treatment}

All-trans retinoic acid was provided by Professor Chen Zhu (Ruijin Hospital, Shanghai Second Medical University). RA treatment of the hepatoma cells was performed as described previously[8]. An amount of $2.4 \times 10^{5} \mathrm{Q} 3$ hepatoma cells and Q3 transfected by pCMV or pCMV-TTR were seeded in the medium containing RA (final concentration $10 \mu \mathrm{mol} / \mathrm{L}$ ) respectively. The same number of Q3 cells without RA treatment were examined as control, and counted on d 1, d 3, d 5 and d 7 .

\section{RESULTS}

Inhibitory effect of transfected pCMV-TTR on growth rate of hepatoma cells

After the transfection with pCMV-TTR or pCMV as control, the growth rate of hepatoma cells was analyzed by counting cell number at different time intervals. As illustrated in Fig 2 and Tab 1, it was evident, in repeated experiments, that the growth of SMMC-7721 hepatoma cells was inhibited after being transfected with pCMV -TTR as compared to that of the control transfected with pCMV. The rate of inhibition varied from $45 \%$ to $51 \%$. There was no apparent change in cellular morphology, thereby excluding any toxic effects of the transfected TTR cDNA.

\section{Expression of TTR mRNA in transfected hepatoma cells}

Total RNA was isolated from hepatoma cells PLC/PRF/5, Q3 and SMMC-7721 as well as SMMC-7721 transfected with PCMV and PCMV-TTR. The mRNA expression of TTR gene in hepatoma cell lines PLC/PRF/5, Q3 and SMMC-7721 were extremely low to be detectable only by Northern analysis (lanes 6, 5, 4, Fig 3). 
Inhibition of hepatoma cell growth by TTR cDNA

Fig 2. Growth rate of SMMC-7721 transfected with pCMV or pCMV-TTR.

- SMMC-7721 transfected with pCMV.

o SMMC-7721 transfected with pCMV-TTR.

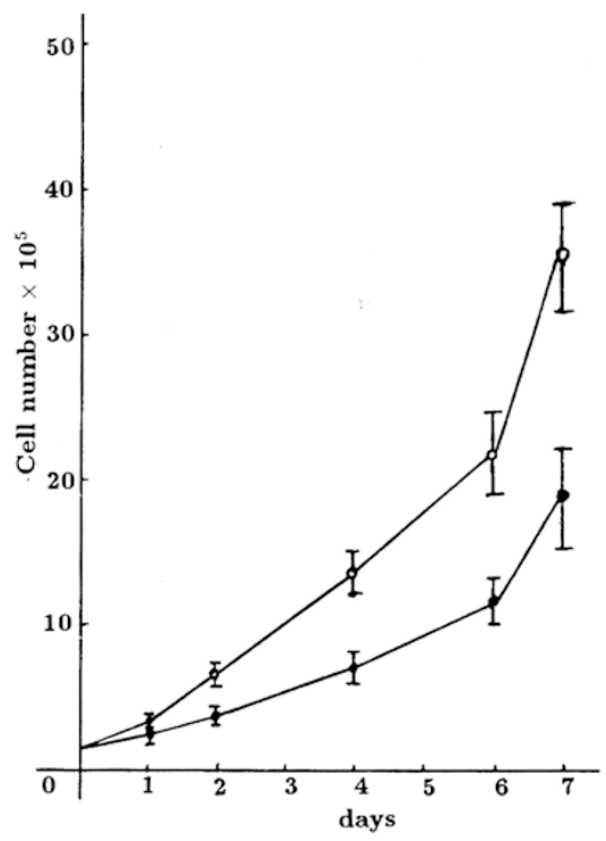

Tab 1. Inhibitory effect of transfected pCMV-TTR on the growth rate of hepatoma cells of SMMC-7721 cell line

\begin{tabular}{lccc}
\hline & \multicolumn{3}{c}{ Cell counts at different time intervals $\left(\times 10^{5}\right)$} \\
\hline Culture & $48 \mathrm{~h}$ & & \\
\cline { 2 - 4 } & $7.02 \pm 1.65$ & $96 \mathrm{~h}$ & $144 \mathrm{~h}$ \\
\hline $\begin{array}{c}\text { pCMV } \\
\text { treated } \\
\text { pCMV-TTR } \\
\text { treated }\end{array}$ & $3.94 \pm 0.50(* 45.4 \%)$ & $7.44 \pm 1.04(* 51.0 \%)$ & $12.31 \pm 1.84(* 48.1 \%)$ \\
\hline
\end{tabular}

The percentage in brackets indicated the growth inhibitory rate.

* denoted the difference of statistical significance $(\mathrm{P}<0.01)$, between treated and control groups; For each value, $n=12$.

Meanwhile, the same low level of expression was observed in hepatoma cells transfected with pCMV alone (lane 1, Fig 3). However, in hepatoma cells SMMC-7721 transfected with pCMV-TTR, an abundant quantity of mRNA transcripts $(0.7 \mathrm{~kb})$ was identified (lanes 2, 3, Fig 3). Therefore, it implied that the expression of TTR in hepatoma cells was possibly correlated with its inhibitory effect on the growth behavior of the transfected hepatic cancer cells. 
Liu CT et al.

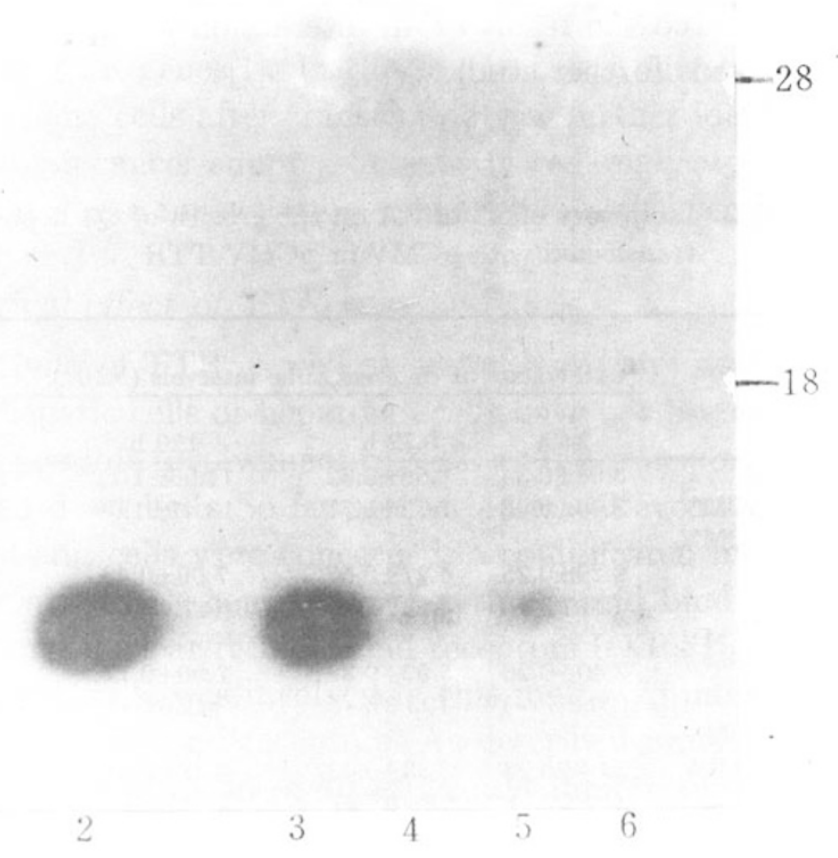

Fig 3. Expression of human TTR mRNA in hepatoma cells. Total RNAs $(20 \mu \mathrm{g})$ from each cell line were resolved by formaldehyde/agarose gel electrophoresis transferred to nitrocellulose membranes, and hybridized with ${ }^{32} \mathrm{P}$-labeled human TTR cDNA. Blots were washed and exposed to X-ray film for $7 \mathrm{~d}$. Positions of RNA at 28s and 18s are shown. Hepatoma cell lines: PLC/PRF/5 (lane 6), Q3 (lane 5), SMMC-7721 (lane 4). Hepatoma cells SMMC-7721 transfected with pCMV (lane 1), hepatoma cells SMMC-7721 transfected with pCMV-TTR (lanes 2, 3).

Effect of retinoic acid on growth behavior of untransfected and transfected hepatoma cells

As described previously, all-trans retinoic acid itself has some inhibitory effect on human hepatoma cell lines at a concentration of $10 \mu M[9]$ and TTR has been reported to be related to the transport mechanism of retinoic acid. The retinoic acid was added into the culture medium of hepatoma cells which were untransfected or transfected with pCMV or pCMV-TTR. Results were shown in Tab 2. It was evident that all-trans retinoic acid itself has some inhibitory effect on the growth rate of hepatoma cell line Q3 and also enhanced the growth inhibitory effect of TTR transfected hepatoma cells (at $72 \mathrm{~h}, 120 \mathrm{~h}$ and $168 \mathrm{~h}$ after treatment of retinoic acid). As no apparent alteration in cell morphology and no detachment of hepatoma cells were observed after being treated with retinoic acid at a concentration of $10 \mu M$, it seems unlikely that the reduction of cell numbers would be attributable to the cytotoxic effect of retinoic acid. However, from the above data, it was uncertain 
Inhibition of hepatoma cell growth by TTR cDNA

whether it was a combinational effect of 2 independent events by retinoic acid and TTR or it represented the result of an interaction between retinoic acid and TTR products. This needs further studies.

Tab 2. Inhibitory effect of RA on the growth of Q3 hepatoma cells transfected with pCMV or pCMV-TTR

\begin{tabular}{ccccc}
\hline \multirow{5}{*}{ Culture } & \multicolumn{5}{c}{ Cell counts at different time intervals $\left(\times 10^{5}\right)$} \\
\cline { 2 - 5 } & $24 \mathrm{~h}$ & $72 \mathrm{~h}$ & $120 \mathrm{~h}$ & $168 \mathrm{~h}$ \\
\hline Q3 & $3.04 \pm 0.34$ & $7.52 \pm 0.32$ & $11.96 \pm 1.11$ & $17.20 \pm 0.85$ \\
Q3-pCMV & $3.00 \pm 0.48$ & $7.72 \pm 0.77$ & $13.41 \pm 1.08$ & $18.98 \pm 1.19$ \\
Q3-pCMV- & & & & \\
TTR & $2.29 \pm 0.25$ & $4.27 \pm 0.57$ & $7.09 \pm 0.43$ & $9.42 \pm 0.64$ \\
Q3-pCMV & $(23.7 \% *)$ & $(44.7 \% *)$ & $(47.1 \% *)$ & $(50.4 \% *)$ \\
+RA & $2.40+0.26$ & $5.92+0.38$ & $7.90+0.77$ & $11.45+0.82$ \\
Q3-pCMV- & $(20.0 \% * *)$ & $(23.3 \% *)$ & $(41.0 \% *)$ & $(39.7 \% *)$ \\
TTR+RA & $2.04 \pm 0.28$ & $3.33 \pm 0.43$ & $4.48 \pm 0.61$ & $6.28 \pm 0.52$ \\
& $(32.0 \% *)$ & $(56.9 \% *)$ & $(66.6 \% *)$ & $(66.9 \% *)$ \\
& & $(22.0 \%++)$ & $(36.8 \%+)$ & $(33.3 \%+)$ \\
\hline
\end{tabular}

Q3-pCMV: Hepatoma cell line Q3 transfected with pCMV; Q3pCMV-TTR: Q3 transfected with pCMV-TTR; Q3-pCMV+RA: Q3 transfected with pCMV and treated with retinoic acid; Q3-pCMVTTR+RA: Q3 transfected with pCMV-TTR and treated with retinoic acid. Data were the mean value of 12 determinations. Percentage in brackets indicated the inhibitory rate referring Q3-pCMV as con$\operatorname{trol}(*, * *)$, the inhibitory rate referring the use of Q3-pCMV-TTR as $\operatorname{control}(+,++)$.

$*,+$ denoted the difference of statistical significance $(\mathrm{P}<0.01)$.

$* *,++$ denoted the difference of statistical significance $(\mathrm{P}<0.05)$.

\section{DISCUSSION}

TTR as a candidate for cancer-suppressor gene for human hepatic cancer

Transthyretin(TTR) has been described as a gene linked to a hereditary diseasefamilial amyloidosis, in which mutation of TTR gene of germ cells could result in a widespread amyloid degeneration in the central nervous and cardiovascular systems. The gene has been cloned [10] and coded for a polypeptide of 127 amino acids, which formed a tetramer protein resistant to heat and acid treatment. In our laboratory, during the analysis of a subtractive cDNA library constructed from mRNA of normal human liver minus that of hepatic cancer, one of the cDNA clones, differentially expressed in normal liver and suppressed at mRNA expression in liver cancer, was sequenced. Unexpectedly, the cDNA was completely homologous to TTR at its coding region[1]. It has been further revealed that TTR gene had a deleted lesion in 
nearly half of DNA samples from the resected primary liver cancer tissues. Moreover, the mRNA expression was suppressed in 8 out of 9 hepatic cancer samples with or without deletion in TTR genes[1]. In this study, the in vitro inhibitory effect of TTR on human hepatoma cells after transfection was further identified. According to the criteria of a human cancer-suppressor gene, it was implicated that TTR might be one of the candidates as a novel antioncogene for human liver cancer.

\section{The possible biological effect of TTR gene}

The biological activity of TTR as well as its mechanism of action on the growth or differentiation of hepatic cells or hepatoma cells have not been well explored. As a serum protein, the possible involvement of TTR in the transport of thyroxine and retinoic acid has been described. So far as the biological events of the interaction between retinoic acid and cells were concerned, a complicated mechanism must be involved, relating to various elements such as retinoic acid binding protein (RBP) [11,12], TTR[13,14], and nuclear retinoic acid receptors RXRs[15] and RARs[16-19] etc. It was unclear how TTR was involved in this multistep interaction of retinoic acid with its binding proteins and receptors. As described previously by Ai et al[8, 9], retinoic acid at a concentration of $10 \mu M$ could inhibit the growth of hepatic cancer cells as well as some phenotypic changes without evidence of cytotoxic damage of the cells. In this study, the retinoic acid at $10 \mu M$ could hinder the growth of human hepatoma cells and further enhance the effect on TTR transfected cells. However, it was uncertain the results were attributable to the accumulated effect of retinoic acid and TTR, or to their interaction in the cells. Moreover, as the amount of retinoic acid used in this study as well as those in previous reports [8,9] was much higher than the physiological level. Further studies are required to elucidate the mechanism of TTR involved in the growth behavior of hepatoma cells and its possible interaction with all-trans retinoic acid.

\section{REFERENCES}

[1] Gu JR, Jiang HQ, He LP, et al. Transthyretin (prealbumin) gene in human Primary hepatic cancer. Sci China 1991[B]; 34:1312-8.

[2] Costa PP, Figueira AS, Bravo FR. Amyloid fibril protein related to prealbumin in familial amyloidotic polyneuropathy. Proc Natl Acad Sci USA 1978; 75:4499-503.

[3] Pras M, Prelli F, Franklin EC, Frangione B. Primary structure of an amyloid prealbumin variant in familial polyneurophy of Jewish origin. Proc Natl Acad Sci USA 1983; 80:539-42.

[4] Tawara S, Nakazato M, Kangawa K, Matsuo H, Araki S. Identification of amyloid prealbumin variant in familial amyloidotic polyneuropathy (Japanese type). Biochem Biophys Res Commun 1983; 116:880-8.

[5] Felgner PL, Gadek TR, Holm M, et al. Lipofection: a highly efficient, lipid-mediated DNAtransfection procedure. Proc Natl Aca d Sci 1987; 84:7413-7.

[6] Chomczynski P, Sacchi N. Single-step method of RNA isolation by acid guanidinium thiocyanatephenol-chloroform extraction. Analytical Biochem 1987; 162:156-9.

[7] Maniatis T, Fritsch EF, Sambrook J. Molecular Cloning: a laboratory manual. Cold Spring 


\section{Inhibition of hepatoma cell growth by TTR cDNA}

Harbor Laboratory, Cold Spring Harbor, New York 1982:202-6.

[8] Ai ZW, Zha XL, Liu Y, Chen HL. Some reverse effects of retinoic acid on the cytosolic phenotype of human hepatocarcinoma cell line. Acta Biochimica et Biophysica Sin 1990; 22:135-40.

[9] Ai ZW, Zha XL, Tang H, Chen HL. The reverse effect of retinoic acid on human hepatocarcinoma cell line-biological studies. Chinese Biochem J 1990; 6:163-8.

[10] Mita S, Maeda S, Shimada K, Araki S. Cloning and sequence analysis of cDNA for human prealbumin. Biochem Biophys Res Commun 1984; 124:558-64.

[11] Sani BP, Reddy LG, Singh RK, Arello EA. A new retinoids-binding protein with a low molecular weight. Biochem Biophys Res Commun 1991; 175:1064-9.

[12] Didierjean L, Durand B, Saurat J-H. Cellular retinoic acid-binding protein type $2 \mathrm{mRNA}$ is overexpressed in human psoriatic skin as shown by in situ hybridization. Biochem Biophys Res Commun 1991; 180:204-8.

[13] Gustavsson A, Engstrom U, Westermark P. NormM transthyretin and synthetic transthyretin fragments form amyloid-like fibrils in vitro. Biochem Biophys Res Commun 1991; 175:1159-64.

[14] Sasaki H, Yoshioka N, Takagi Y, Sakaki Y. Structure of the chromosomal gene for human serum prealbumin. Gene 1985; 37:191-7.

[15] Mangelsdorf D J, Ong ES, Dyck JA, Evans RM. Nuclear receptor that identifies a novel retinoic acid response pathway. Nature (London) 1990; 345:224-9.

[16] Graupner G, Wills KN, Tzukerman M, Zhang X-K, Pfahl M. Dual regulatory role for thyroidhormone receptors allows control of retinoic acid receptor activity. Nature (London) 1989; 340:653-6.

[17] Hoffmann B, Lehmann JM, Zhang X-K, et al. A retinoic acid receptor-specific element controls the retinoic acid receptor-promoter. Mol Endocrinol 1990; 4:1727-36.

[18] Evans RM. The steroid and thyroid hormone receptor superfamily. Science 1988; 240:889-95.

[19] Riaz-ul-Haq, Pfahl M, Chytil F. Differential effects of all trans and 13-cis-retinoic acid on mRNA levels of nuclear retinoic acid receptors in rat lung and liver. Biochem Biophys Res Commun 1991; 180:1137-44.

Received 29-11-1993. Revised 28-2-1994. Accepted 5-3-1994 